\title{
Estratégias de Aprendizagem no Ensino Técnico Profissional
}

\author{
Fabio Alexandre Pereira Scacchetti - Universidade Tecnológica Federal do Paraná, Apucarana, Brasil \\ Katya Luciane de Oliveira - Universidade Estadual de Londrina, Londrina, Brasil \\ Ana Elisa da Costa Moreira - Universidade Estadual de Londrina, Londrina, Brasil
}

\begin{abstract}
Resumo
Esta pesquisa teve como foco a adaptação da escala validada de Estratégias de Aprendizagem, voltada ao ensino fundamental, de forma que possibilitasse o levantamento de evidências de validade fatorial para seu emprego no ensino técnico-profissional. Também visou levantar as estratégias de aprendizagem empregadas por esses alunos. Participaram 709 estudantes do ensino técnico-profissional, provenientes de uma instituição privada e outra pública federal. Por meio dos resultados apresentados, foi possível evidenciar a validade do instrumento que confirmou a estrutura de três fatores na análise fatorial exploratória, apontada em estudos anteriores. Os alfas de Cronbach da escala toda (0,74), subescalas Ausência de Estratégias de Aprendizagem (0,77) e Estratégias Cognitivas $(0,73)$ foram considerados aceitáveis com exceção a subescala de Estratégias Metacognitivas $(0,57)$. O estudo também apontou que parte significativa dos estudantes relata recorrer às estratégias de aprendizagem, sobretudo a utilização de estratégias cognitivas. Os dados foram discutidos à luz das implicações psicoeducacionais.

Palavras-chave: análise fatorial, ensino profissionalizante, aprendizagem, estratégias de aprendizagem cognitivas, estratégias de aprendizagem metacognitivas
\end{abstract}

Learning Strategies in Vocational Technical Education

\begin{abstract}
This research focuses on the adaptation of the validated scale of Learning Strategies, aimed at primary school, so that it would enable raising factorial validity evidence for its use in professional technical education. We also sought to assess the learning strategies employed by these students. 709 students participated in the vocational technical education from a private institution and other of federal government. Through the results, it was possible to demonstrate the validity of the instrument that confirmed the three-factor structure in the exploratory factor analysis, pointed out in previous studies. The Cronbach alphas for the whole scale (.74), subscales Lack of Learning Strategies (.77) and Cognitive Strategies (.73) were acceptable except for the Metacognitive Strategies subscale (.57). The study also found that a significant proportion of students reported use of learning strategies, especially the use of cognitive strategies. The data were discussed in the light of psych educational implications. Keywords: factor analysis; professional technical education, learning, cognitive learning strategies, metacognitive learning strategies
\end{abstract}

\section{Estrategias de Aprendizaje en la Enseñanza Técnico Profesional}

\section{Resumen}

Esta investigación se centró en la adaptación de la escala de Estrategias de Aprendizaje, dirigida a la enseñanza primaria, de forma que posibilitase el levantamiento de evidencias de validez factorial para su uso en la enseñanza técnico profesional. También intentó verificar las estrategias de aprendizaje empleadas por esos alumnos. Participaron 709 estudiantes de enseñanza técnico profesional, provenientes de una institución privada y otra pública. A través de los resultados, fue posible evidenciar la validez del instrumento que confirmó la estructura de tres factores en el análisis factorial exploratorio, señalada en estudios anteriores. Los alfas de Cronbach de toda la escala $(0,74)$, sub-escalas Ausencia de Estrategias de Aprendizaje $(0,77)$ y Estrategias Cognitivas $(0,73)$ fueron considerados aceptables excepto para la sub-escala de Estrategias Meta-cognitivas $(0,57)$. El estudio también señaló que una parte significativa de los estudiantes informó recurrir a estrategias de aprendizaje, principalmente a la utilización de estrategias cognitivas. Los datos fueron discutidos basándose en las implicaciones psico-educativas.

Palabras clave: análisis factorial, enseñanza profesional, aprendizaje, estrategias de aprendizaje cognitivas, estrategias de aprendizaje meta-cognitivas

\section{Introdução}

\section{Contextos da Educação Profissional no Brasil}

A ampliação da educação profissional no Brasil surge a partir do ano de 1940, com sistemas de educação oferecidos tanto pelo sistema público como privado. Durante esse período, ocorreu a publicação das Leis Orgânicas do Ensino Profissional. Em 30 de janeiro de 1942, o decreto-lei $\mathrm{n}^{\circ} 4.073$ organizou o ensino industrial. Um ano depois, em 28 de dezembro de 1943, publicou-se o decreto-lei no 6.141 que estabelecia a Lei Orgânica do ensino comercial e em 20 de agosto de 1946 foi publicado o decreto-lei $n^{\circ} 9.613$ que regulamentou a Lei Orgânica do ensino agrícola.

A Lei de Diretrizes e Bases da Educação Nacional, de 1961, visava uma educação tecnicista, estabelecendo o modelo empresarial no contexto educacional. Em 1971, com a Lei no 5.692, a formação 
profissional tornou-se responsabilidade do ensino no $2^{\circ}$ grau (ensino médio na atualidade), quando surgiu uma grande quantidade de escolas profissionalizantes. Essa iniciativa, obrigatória no período de ditadura militar, não obteve êxito, pois havia dificuldades de implantação do projeto em razão da crise econômica que o país passava (Padilha, 2001).

Nos anos iniciais a década de 1980, a Lei 7.044/82 revogou a anterior (Lei $\mathrm{n}^{\circ}$ 5.692/1971). A profissionalização no $2^{\circ}$ grau, até então imposta, tornou-se liberada. Para Kuenzer (2002), havia críticas quanto à qualidade da educação profissionalizante ministrada, na qual os resultados não eram concretos em algumas instituições. A modernização do processo industrial ocorria de forma lenta. Simultaneamente, no campo educacional profissionalizante, criaram-se duas realidades distintas, enquanto de um lado existia a dificuldade governamental em âmbito de definição política para o sistema, do outro se construía um sistema liderado pelo Serviço Nacional de Aprendizagem Industrial (SENAI) e pelo Serviço Nacional de Aprendizagem Comercial (SENAC), originados durante a década de 1940.

No decorrer de mudanças mundiais nas estruturas de trabalho de acordo com as reestruturações produtivas, o governo adotou um novo projeto pedagógico, no qual a principal contribuição era a reforma do ensino técnico. Essas mudanças foram precedidas pela Lei de Diretrizes e Bases (LDB), juntamente com o decreto $n^{\circ}$ 2.208, de 17 de abril de 1997. No corpo da Lei, "educação profissional" é definida como o supra sistema que compreende os níveis básico, técnico e tecnológico. Após a definição de suas finalidades, teve como objetivo buscar superar a dualidade socialmente estabelecida entre educação geral e profissional (Padilha, 2001).

A competição mundial, o desenvolvimento da tecnologia e a busca pela utilização dos recursos de forma inteligente e produtiva tornam a capacitação profissional um ponto extremamente crítico (Castro, 2003). A educação profissional é um campo complexo e multifacetado, tratando-se de uma área da educação formal que é pouco pesquisada no âmbito acadêmico.

A educação profissional demostra sua importância na atual conjuntura, a procura pelos cursos e a quantidade ofertada têm aumentado consideravelmente, principalmente após a retomada da expansão da rede federal de educação profissional e tecnológica com a edição da Lei n ${ }^{\circ} 10.683$, de 28 de maio de 2003 , revogando a lei anterior que impedia sua ampliação. O Programa Nacional de Acesso ao Ensino Técnico e Emprego (Pronatec), criado pelo Governo Federal em 2011, tem como objetivo a ampliação da oferta de cursos de educação profissional e tecnológica. O Sistema de Seleção Unificada da Educação Profissional e Tecnológica (Sisutec), criado em 2013 e gerenciado pelo Ministério da Educação (MEC), oferece vagas gratuitas em cursos técnicos para candidatos participantes do Exame Nacional do Ensino Médio (Enem). As vagas são oriundas de instituições públicas e privadas de ensino superior e de educação profissional e tecnológica.

Face ao que foi apresentado, parece relevante a busca de alternativas para mensurar os fenômenos psicoeducacionais nesse tipo de formação educacional. Posto isso, torna-se importante compreender quais são as estratégias de aprendizagem empregadas por esses estudantes para entender melhor e como se configura o próprio processo de aprender nessa especificidade de formação.

\section{Consideracões sobre as Estratégias de Aprendizagem}

Para que haja aprendizado, o indivíduo tem a necessidade de organizar, entender e compreender a informação, processos considerados básicos em qualquer aprendizagem e realização cognitiva. $\mathrm{O}$ desenvolvimento de novas formas ou estratégias para aprender ocorre durante todo o processo de desenvolvimento do indivíduo, sendo dependente das contingências as quais este está inserido (Perassinoto, Boruchovitch, \& Oliveira, 2012).

As estratégias de aprendizagem, também conhecidas como métodos de aprendizagem, podem ser utilizadas pelo indivíduo para diferentes e variados propósitos, como a realização de tarefas. As estratégias de aprendizagem são atitudes que podem melhorar/ potencializar o processamento da informação (Boruchovitch, 1999; Boruchovitch \& Santos, 2006). Os alunos bem-sucedidos demonstram repertório vasto das estratégias, sabendo quando, como e onde utilizá-las, alcançando assim maior facilidade nos trabalhos escolares.

A literatura científica sobre as estratégias de aprendizagem aponta uma diversidade de classificação para elas. Ao se considerar uma forma de classificação mais geral, é possível agrupá-las em duas esferas, quais sejam, as estratégias cognitivas e as metacognitivas (Boruchovitch, 1999; Boruchovitch \& Santos, 2006; Dembo, 1994; Garner \& Alexander, 1989; Oliveira, Boruchovitch, \& Santos, 2010, entre outros). Pintrich (1989), Dembo (1994), Jamieson (1995) e Boruchovitch 
(1999) concordam que as estratégias cognitivas tangem o comportamento de compreensão das partes para se chegar ao entendimento do todo. Ações, como organizar, armazenar e elaborar as informações, usando meios como repetição, releitura, grifar, resumir, utilizar anotações são típicas do aluno que apresenta em seu arcabouço as estratégias cognitivas.

As estratégias metacognitivas estão relacionadas a procedimentos viabilizadores utilizados pelo indivíduo no intuito de planejar, monitorar e regular seu pensamento, envolvendo o controle e execução do processo. Elas são utilizadas para avaliar a utilização das cognitivas. O nível de complexidade é considerado alto, visto que o indivíduo deve ter autoconhecimento, conhecer as atividades ou tarefas a serem executadas, além de informações acerca das possíveis estratégias de aprendizagem a serem utilizadas, considerando o momento de execução para cada estratégia. É necessário também ter conhecimento do próprio processo de aprendizagem para compreender quando alguma informação não foi entendida e para que então o comportamento possa ser regulado e modificado em relação ao estudo (Dasereau, 1985; Dembo, 1994; Flavell, 1987; Veenman, Wilhelm, \& Beishuizer, 2004).

Estudantes estratégicos apresentam quatro características, primeiramente, avaliam as tarefas de forma crítica e, de acordo com essa análise, definem metas para curto prazo e objetivos gerais para estudar. Uma terceira característica é que possuem conhecimento de alternativas das táticas cognitivas a serem empregadas. Por fim, são capazes de julgar táticas empregadas no intuito monitorar e regular o próprio comportamento de acordo com os objetivos (Hadwin, Winne, Stockley, Nesbit, \& Woszczyna, 2001). Quanto maior o repertório de estratégias de aprendizagem do aluno, melhor as chances de êxito escolar (Oliveira, Boruchovitch, \& Santos, 2011; Valle, Cabanach, Cuevas, Rodriguez, \& Baspino, 1998).

Conforme apontam Stahl, King e Eliers (1996), o uso das estratégias de aprendizagem vem sendo objeto de pesquisas desde o início do século XX, todavia com destaque da temática após a década de 1980. A partir desse ponto, começaram a surgir instrumentos, principalmente na literatura internacional. Muitos desses estudos procuraram apontar as estratégias de aprendizagem utilizadas por estudantes durante a resolução de tarefas propostas (Boruchovitch, Costa \& Neves, 2005; Boruchovitch \& Santos, 2006). No âmbito nacional, a construção de instrumentos e o estudo das estratégias de aprendizagem se fortaleceram a partir da década de 1990. Os estudos eram, no geral, descritivos, mas aplicados a outras etapas do ensino formal que não o ensino técnico profissional. Ao longo do levantamento, realizado nas plataformas do Scielo, CAPES e Pepsic, não foram encontradas pesquisas acerca do tema no ensino técnico profissional, especialmente aquelas que visassem à construção de formas de mensuração para atender a esse perfil escolar.

$\mathrm{Na}$ sequência, serão apresentados, na ordem cronológica, os estudos nacionais que focaram a construção e ou a adaptação e a validação de instrumentos acerca das estratégias de aprendizagem. Embora, no presente trabalho, sejam apresentados os instrumentos desenvolvidos em âmbito nacional, cabe citar que, em âmbito internacional, são usadas medidas como o Self-Regulated Learning Interview Schedule (SRLIS) de Zimmerman e Martinez-Pons (1986); o Learning and Study Strategies Inventory (LASSI) desenvolvido por Weinstein, Zimmerman e Palmer (1988) e o Motivated Strategies for Learning Questionnaire (MSLQ) de Pintrich e Groot (1989).

A entrevista SRLIS, traduzida e adaptada por Boruchovitch (1995) constitui-se de 16 itens, com o objetivo de investigar a utilização das estratégias de aprendizagem em sala de aula, em casa e durante as tarefas para casa. Gomes e Boruchovitch (2002) desenvolveram o jogo BMG para averiguar a percepção dos alunos quanto aos procedimentos mais apropriados para a aprendizagem. Constitui-se de vinte questões com três alternativas para resposta. Cada cartela possui dezesseis, dos vinte itens. É realizada a leitura de cada item e os alunos marcam as respostas na cartela, ao final são relidos os itens com as respostas aguardadas e contado o escore. O jogo foi aplicado em 29 alunos da $4^{a}$ Série do ensino fundamental de uma escola pública. Auxiliar ao jogo, foi desenvolvido um formulário para avaliar a metacognição a ser respondido ao final da atividade, conforme Gomes (2002).

Cardoso (2002) utilizou o LASSI, estudou evidências de aprendizagem e suas relações às metas de realização. Foram utilizados mais dois instrumentos na pesquisa, relacionados à orientação motivacional e à percepção do ambiente de aprendizagem. Participaram 106 estudantes de informática e tecnologia de uma instituição pública de ensino superior do Paraná. Os resultados acerca das estratégias mostraram que a turma de informática relatou maior organização, concentração e atenção às tarefas, todavia o grupo de pedagogia utilizou estratégias de suporte que auxiliavam a aprender ou recordar a informação. 
Utilizando-se do MSLQ, Machado (2005) trabalhou com o ensino superior. Tomou o referido instrumento como base, tradução e adaptação para o contexto nacional, que resultou na construção do "Inventário de motivação e estratégias em cursos superiores" de Machado, Bzuneck e Guimarães (2004). Machado (2005) pesquisou os fatores motivacionais, contexto e utilização de estratégias de aprendizagem, como fatores para o aluno persistir ou desistir do curso. Participaram 171 alunos de uma universidade pública do Paraná. O estudo gerou cinco fatores para a motivação (meta aprender, extrínseca, autoconceito, responsabilidade e crenças de controle sobre aprendizagem e ansiedade, com alfa de Cronbach entre 0,62 e $0,85)$. Ficaram três fatores para a utilização de estratégias de aprendizagem (estratégias gerais I, II e aplicação de esforço, com alfa de Cronbach entre 0,56 e 0,85), todavia não foi confirmada a relação esperada entre a evasão e os dados apresentados.

Bartalo (2006) utilizou o LASSI, que adaptou para universitários do estado de São Paulo e Paraná, totalizando a amostra de 833 estudantes. Teve como objetivo abordar estratégias de estudo e aprendizagem que eram adotadas na internet. É válido ressaltar que, dos 77 itens originais, prevaleceram 71 e também, os 11 itens inclusos. Como resultado, o devido instrumento apresentou 10 fatores com alfa acima de 0,60.

A escala de Estratégia metacognitiva para leitura construída por Joly (2006) teve como desafio mensurar quais estratégias metacognitivas eram utilizadas pelos alunos de ensino fundamental e a frequência na utilização delas. $\mathrm{O}$ instrumento foi composto por 13 afirmações em escala Likert e foi dividido em três fatores, suporte de leitura, resolução dos problemas na compreensão e estratégias de leitura globais. Conforme estudo de Carvalho (2006) e Piovezan e Castro (2008), o alfa de Cronbach foi de 0,73 , cujas cargas fatoriais apresentaram variação entre 0,33 e 0,77 .

Com base na literatura destinada ao ensino fundamental, Serafim e Boruchovitch (2007) produziram instrumentos para avaliar os alunos quanto à estratégia de pedido de ajuda. Criaram um instrumento chamado de prancha, no qual uma história com situação problema abordava sobre pedir ajuda e para quem seria esse pedido, conhecendo a concepção de professores e alunos. Serafim (2009) aplicou o instrumento com o objetivo de verificar a concepção do pedido de ajuda e relações dessa estratégia com o gênero, a motivação e autoeficácia dos estudantes. O estudo contou com a participação de 159 alunos de $2^{\mathrm{a}}$ a $4^{\mathrm{a}}$ série do ensino fundamental de uma escola pública do município de Campinas. Os resultados mostraram que os estudantes utilizavam essa estratégia, sempre solicitando de forma verbal. Também apontou diferença conforme o avanço das séries, os de $2^{a}$ série se diferenciaram significativamente perante as outras séries por apresentarem compreensão negativa dessa estratégia. Quanto ao gênero, não foram constatadas relações significativas. Foi verificada correlação positiva com a crença de autoeficácia e negativa com a motivação.

Portilho e Ferreira (2005) e Ferreira (2007) estudaram a utilização de estratégias de aprendizagem por alunos diante de uma situação-problema de matemática. Participaram do estudo 20 alunos e 1 (um) professor de uma escola da rede estadual, na região metropolitana de Curitiba. Os instrumentos utilizados foram entrevista semiestruturada (com 12 questões abertas acerca da utilização de estratégias metacognitivas na avaliação da aprendizagem, planejamento e quanto à regulação). O segundo instrumento adaptado foi um roteiro de 56 itens, no qual o pesquisador assinalava quando o aluno apresentava tal estratégia. Os itens continham estratégias de apoio (seis), estratégias de seleção da informação (sete), estratégias de processamento, elaboração e organização da informação (14), memorização (seis) e estratégias de personalização (23). O resultado apresentado foi o descompasso quando se comparou o ensino e o desejo por aprender, já que a pesquisa mostrou as estratégias utilizadas pelo professor e por alunos.

Em sua pesquisa, Oliveira (2008) buscou avaliar as propriedades psicométricas de uma escala de estratégias de aprendizagem desenvolvida por Boruchovitch e Santos (2004). O estudo contou com a participação de estudantes do ensino fundamental. Como resultado, a pesquisa apresentou que 37 itens tiveram boa carga fatorial, sendo agrupados três fatores que também apresentaram consistência interna. A versão final da escala de Boruchovitch e Santos (2004) e validada por Oliveira et al. (2010), nesse novo estudo de Oliveira et al., (2010), ficou formatada com 31 itens. O instrumento novamente apresentou evidências de validade, confirmando uma estrutura de três fatores (estratégias cognitivas, estratégias metacognitivas e ausência de estratégias de aprendizagem) quanto a seu conteúdo e consistência dos resultados. Cabe acrescentar que a versão do instrumento empregado na presente pesquisa corresponde à versão do instrumento com 31 itens, validada e publicada.

Oliveira et al. (2010) teve como objetivo evidenciar a validade de construtos similares, entre a escala 
de Motivação para Aprendizagem (EMAPRE) e escala de Avaliação das Estratégias de Aprendizagem para o Ensino Fundamental (EAVAP-EF). O estudo comprovou a evidência de validade concorrente entre os construtos, na qual foram encontradas correlações fracas e moderadas nos fatores pertencentes às duas escalas. O estudo de Pascualon (2011) teve como proposta construir a Escala de Metacognição (EMETA) e evidenciar validade e precisão da escala para crianças com idade entre nove e doze anos. A análise fatorial apresentou evidência de apenas um único fator, a metacognição.

Em face da importância da utilização adequada das estratégias de aprendizagem, e também da carência de instrumentos que apresentem evidências de validade utilizadas na mensuração em âmbito nacional, o presente estudo se propõe à adaptação da escala validada de Estratégias de Aprendizagem, voltada ao ensino fundamental, de forma que possibilite o levantamento de evidências de validade fatorial para seu emprego no ensino técnico profissional. Também visa levantar, de forma descritiva, as estratégias de aprendizagem empregadas por esses alunos.

\section{Método}

\section{Participantes}

Participaram 709 estudantes do ensino técnico profissional, totalizando 652 alunos provenientes de uma unidade do Serviço Nacional de Aprendizagem Industrial (SENAI) e 57 estudantes do ensino médio técnico de uma Universidade Tecnológica Federal do Paraná (UTFPR). O sexo feminino representou 65,6 \% $(n=465)$ e o masculino $34,4 \%(n=244)$. A idade média dos estudantes foi de 18 anos e 2 meses $(D P=4,39)$, sendo a idade mínima de 13 anos e máxima de 49 anos. Participaram alunos oriundos de diferentes áreas, sendo que 26,8\% da Eletromecânica, 26,2\% da Biotecnologia, $16,9 \%$ da Informática, $12,3 \%$ da Manutenção Automotiva, 8,0\% do Vestuário, 5,6\% da Automação Industrial e 4,1\% da Logística. Desses cursos citados, 47,15\% dos alunos cursavam o $1^{\circ}$ semestre; $34,3 \%$, o $4^{\circ}$ semestre; $11,3 \%$; o $2^{\circ}$ semestre; $4,2 \%$. o $3^{\circ}$ semestre e $2,7 \%$, o $5^{\circ}$ semestre.

\section{Instrumentos}

Utilizou-se a Escala de Avaliação das Estratégias de Aprendizagem para o Ensino Fundamental (EAVAP-EF), com 31 itens, de autoria de Oliveira et al. (2010). Dos itens, 11 (1, 2, 4, 5, 9, 10, 11, 14, 16, 17 e 20) apontam para a utilização de estratégias cognitivas, 7 itens $(6,13,18,22,27,29$ e 31) para as estratégias metacognitivas e $13(3,7,8,12,15,19,21,23,24,25,26,28$ e 30) apontam para a ausência de utilização de estratégias metacognitivas disfuncionais. $\mathrm{O}$ instrumento tem estudos de validade aferidos pela análise fatorial exploratória e foi adaptado para a realidade do ensino técnico profissional, efetuados por Scacchetti e Oliveira (2012). No total, foram adaptados 12 itens $(2,3,4,8,12,18,19$, $23,24,25,26$ e 28$)$. As questões propostas atenderam a uma escala Likert de três pontos, na qual foram atribuídas as opções sempre ( 2 pontos), às vezes (1 ponto) e nunca ( 0 ponto). Os sujeitos leem as questões e as respondem, por exemplo: "Você costuma grifar as partes importantes do texto para entender melhor?".

Cabe ressaltar que, após a adequação do instrumento, que foi realizada por Scacchetti e Oliveira (2012), os itens adaptados dos instrumentos utilizados para a coleta de dados passaram por uma avaliação de três juízes (sendo dois doutores especialistas da área de estratégias de aprendizagem e um mestre da área de ensino profissionalizante) para aferição quanto à perda de conotação desses itens. Os itens para adaptação foram enviados para os juízes juntamente com uma taxionomia do significado das estratégias de aprendizagem, também foi dado um prazo de 30 dias para a devolução das avaliações. Os juízes tiveram uma concordância entre si de $80 \%$, desse modo, os itens adaptados foram mantidos, não havendo perda de itens.

\section{Procedimentos de Coleta de Dados}

A coleta de dados levou aproximadamente 60 dias, na qual os participantes assinaram um Termo de Consentimento Livre e Esclarecido, e para os participantes com idade inferior a 18 anos, os responsáveis legais o assinaram. O termo elucidou sobre a pesquisa e objetivos, assim como a liberdade de escolha em sua participação no estudo. A aplicação aconteceu sempre de forma coletiva, em sala de aula, em dia e horário agendados pelas instituições coparticipantes. O pesquisador acompanhou as aplicações, que tiveram duração aproximada de 30 minutos entre a explicação dos questionários e tempo para resposta dos alunos.

\section{Procedimentos de Análise de Dados}

No que concerne aos procedimentos de análise de dados, foi utilizado o software IBM SPSS Statistics 21. Cabe mencionar que, para uma melhor operacionalização dos objetivos, os dados foram organizados em planilha Excel e submetidos à análise das estatísticas 
descritiva (médias e desvio-padrão) e inferencial (análise fatorial exploratória), com o intuito de atender aos objetivos propostos pela pesquisa. Buscou-se alcançar o primeiro objetivo do estudo, que se referiu ao levantamento da evidência de validade de construto, por meio de análise fatorial exploratória.

\section{Consideraçôes Éticas}

Cabe mencionar que a pesquisa atendeu a todos os dispositivos da Resolução 196/96 do Conselho Nacional de Saúde, que trata de pesquisas com seres humanos. Ela foi aprovada pelo Comitê de Ética em Pesquisa da Universidade Estadual de Londrina CEP/ UEL, processo de $n^{\circ} 19251 / 2012$.

\section{Resultados}

Inicialmente, foi realizado o Teste de Esfericidade de Bartlett, para verificar a possibilidade de aplicar o método da análise fatorial exploratória. $\mathrm{O}$ teste indicou uma correlação entre os itens $\left(\mathrm{x}^{2}[465 ; N=\right.$ $709]=3501,122 ; p<0,001)$ e. portanto, uma adequabilidade ao uso da análise fatorial. A medida de adequação da amostra foi averiguada com o índice de Kaiser-Meyer-Olkin (KMO) que foi de 0,804.

A análise fatorial, por componentes principais e com rotação Varimax, indicou estrutura de três fatores para a escala, eigenvalues acima de 1,0 e capazes de explicar $30,07 \%$ da variância total. Os fatores se agruparam da seguinte forma: Fator 1 - Ausência de estratégias metacognitivas disfuncionais, com 12 itens $(3,7,8,12$, 15, 21, 23, 24, 25, 26, 28 e 30); Fator 2 - estratégias cognitivas, com 11 itens $(1,2,4,5,9,10,11,14,16,17$ e 20$)$ e o Fator 3 - estratégias metacognitivas, com 4 itens (6, 13, 22 e 29). A Tabela 1 mostra a distribuição dos itens por fator e suas respectivas cargas fatoriais.

Cabe salientar que a menor carga fatorial foi de 0,36, e a maior carga fatorial foi de 0,65 . O alfa de Cronbach da escala toda foi de 0,74 . Ressalta-se ainda que os itens 18, 27 e 31 (estratégias metacognitivas, conforme literatura) e 19 (ausência de estratégias metacognitivas disfuncionais, conforme literatura) foram excluídos do questionário por não apresentarem carga fatorial, sendo que os itens 18 e 19 foram adaptados pelos autores do presente estudo. A Tabela 2 apresenta os itens organizados nas subescalas ou fatores, assim como os respectivos valores do alfa de Cronbach, demonstrando a consistência interna do instrumento com índices aceitáveis. Todavia, para o fator 3, estratégias metacognitivas, não obteve consistência interna, apresentando um alfa de Cronbach de 0,57.
Cabe a ressalva que, para a subescala de Estratégias Metacognitivas, foram levantados o alpha if deleted, proporcionado pelo software, no intuito de melhorar o índice do alfa de Cronbach, entretanto os valores apresentados no estudo foram os maiores. Conforme mencionado anteriormente, a escala de 31 itens, versão adaptada voltada para o ensino profissionalizante, foi reduzida para 27 itens, dessa forma, os itens 18, 19, 27 e 31 foram excluídos da versão por não apresentarem carga fatorial para os três fatores forçados.

Com o escopo de atender o segundo objetivo, o de identificar as estratégias de aprendizagem utilizadas pelos estudantes do ensino técnico profissional, levantou-se a média de pontos para a escala de 27 itens, que foi de 28,1 $(D P=6,26)$, com pontuação mínima de 8 e máxima de 47 pontos. As pontuações nas subescalas de ausência de estratégias metacognitivas disfuncionais, estratégias cognitivas e estratégias metacognitivas também foram averiguadas e estão descritas na Tabela 3.

A análise de dados indicou a média de pontos obtidos, conforme Tabela 3 , de 12,62 pontos $(D P=$ $3,89)$ para a ausência de estratégias metacognitivas disfuncionais. Com os resultados alcançados a partir dessa análise, é possível observar que 33,1\% dos estudantes $(n=236)$ apresentaram pontuação inferior à média de pontos alcançados, demonstrando a não utilização de estratégias metacognitivas disfuncionais. Cabe ressaltar que os itens do questionário relacionados à pontuação foram invertidos previamente à análise fatorial dos dados. Dessa forma, uma pontuação baixa indica ausência de estratégias metacognitivas disfuncionais. Para utilização de estratégias cognitivas, é possível destacar também que 44,7\% dos estudantes $(n=318)$ atingiram pontuação superior à média, apontando a utilização de estratégias cognitivas. Em relação às estratégias metacognitivas, é possível observar que 37,1\% dos estudantes $(n=263)$ pontuaram acima da média quanto à utilização de estratégias de aprendizagem metacognitivas.

\section{Discussão}

Quanto à evidência de validade fatorial da escala de estratégias de aprendizagem adaptada para o ensino profissionalizante por Scacchetti e Oliveira (2012), novos estudos devem ser realizados com o instrumento. Pois, se por um lado foi confirmada a estrutura de três fatores na análise fatorial exploratória, também apontada em estudos anteriores (Boruchovitch \& Santos, 2004; Boruchovitch et al., 2006; Oliveira, Boruchovitch, 
Tabela 1

Distribuição dos Itens e Respectivas Cargas Fatoriais

\begin{tabular}{|c|c|c|c|c|c|}
\hline Itens & & 1 & 2 & 3 & Comunalidade \\
\hline EA1 & $\begin{array}{l}\text { Você costuma grifar as partes importantes do texto } \\
\text { para aprender melhor? }\end{array}$ & & 0,401 & & 0,221 \\
\hline EA2 & $\begin{array}{l}\text { Quando você esta construindo um texto, costuma } \\
\text { fazer uma lista de ideias antes de começar a } \\
\text { escrever? }\end{array}$ & & 0,401 & & 0,163 \\
\hline EA3 & $\begin{array}{l}\text { Você costuma estudar ou fazer as tarefas escolares } \\
\text { na última hora? }\end{array}$ & 0,438 & & & 0,258 \\
\hline EA4 & $\begin{array}{l}\text { Quando você está assistindo a uma aula, costuma } \\
\text { fazer anotações por conta própria? }\end{array}$ & & 0,538 & & 0,329 \\
\hline EA5 & $\begin{array}{l}\text { Você costuma ler outros textos e livros sobre o } \\
\text { assunto que o professor explicou em aula? }\end{array}$ & & 0,486 & & 0,265 \\
\hline EA6 & $\begin{array}{l}\text { Quando você estuda, costuma perceber que não } \\
\text { esta entendendo aquilo que está estudando? }\end{array}$ & & & 0,606 & 0,403 \\
\hline EA7 & $\begin{array}{l}\text { Você costuma desistir quando uma tarefa é difícil } \\
\text { ou chata? }\end{array}$ & 0,413 & & & 0,218 \\
\hline EA8 & $\begin{array}{l}\text { Você costuma se distrair durante a explicação em } \\
\text { sala de aula? }\end{array}$ & 0,552 & & & 0,399 \\
\hline EA9 & $\begin{array}{l}\text { Você costuma fazer um esquema usando as ideias } \\
\text { principais do texto? }\end{array}$ & & 0,531 & & 0,302 \\
\hline EA10 & $\begin{array}{l}\text { Quando você termina de estudar para uma prova, } \\
\text { costuma fazer questões, para si próprio, para ver se } \\
\text { entendeu bem o que estudou? }\end{array}$ & & 0,528 & & 0,288 \\
\hline EA11 & $\begin{array}{l}\text { Quando você lê um texto, procura escrever com } \\
\text { suas palavras o que entendeu da leitura, para poder } \\
\text { estudar depois? }\end{array}$ & & 0,623 & & 0,390 \\
\hline EA12 & $\begin{array}{l}\text { Você se sente cansado quando estuda, ou faz a } \\
\text { tarefa escolar? }\end{array}$ & 0,503 & & & 0,278 \\
\hline EA13 & $\begin{array}{l}\text { Você percebe quando está com dificuldade para } \\
\text { aprender determinados assuntos ou matérias? }\end{array}$ & & & 0,633 & 0,419 \\
\hline EA14 & $\begin{array}{l}\text { Quando você estuda, lê a matéria e depois fecha o } \\
\text { caderno e fala em voz alta tudo o que entendeu? }\end{array}$ & & 0,487 & & 0,251 \\
\hline EA15 & $\begin{array}{l}\text { Você costuma ficar pensando em outra coisa } \\
\text { quando o professor está dando explicações? }\end{array}$ & 0,630 & & & 0,449 \\
\hline EA16 & $\begin{array}{l}\text { Quando você aprende alguma coisa nova, costuma } \\
\text { tentar relacionar aquilo que está prendendo com } \\
\text { alguma coisa que você já sabia? }\end{array}$ & & 0,441 & & 0,210 \\
\hline EA17 & $\begin{array}{l}\text { Você resume os textos que o professor pede para } \\
\text { estudar? }\end{array}$ & & 0,545 & & 0,297 \\
\hline EA18 & $\begin{array}{l}\text { Quando você recebe uma prova, costuma verificar } \\
\text { o que errou? }\end{array}$ & & & & 0,168 \\
\hline EA19 & $\begin{array}{l}\text { Você escuta música enquanto estuda ou faz a } \\
\text { tarefa escolar? }\end{array}$ & & & & 0,124 \\
\hline
\end{tabular}


Tabela 1

Distribuição dos Itens e Respectivas Cargas Fatoriais (Continuação)

\begin{tabular}{|c|c|c|c|c|c|}
\hline Itens & & 1 & 2 & 3 & Comunalidade \\
\hline EA20 & $\begin{array}{l}\text { Você cria perguntas e respostas sobre o assunto } \\
\text { que esta estudando? }\end{array}$ & & 0,631 & & 0,416 \\
\hline EA21 & $\begin{array}{l}\text { Quando você esta fazendo uma tarefa difícil, } \\
\text { costuma ficar muito nervoso? }\end{array}$ & 0,373 & & & 0,232 \\
\hline EA22 & $\begin{array}{l}\text { Quando você estuda, percebe que não esta } \\
\text { conseguindo aprender? }\end{array}$ & & & 0,635 & 0,426 \\
\hline EA23 & $\begin{array}{l}\text { Depois que você senta para fazer a tarefa escolar, } \\
\text { costuma ficar se levantando todo hora para pegar } \\
\text { algum material? }\end{array}$ & 0,590 & & & 0,358 \\
\hline EA24 & $\begin{array}{l}\text { Você costuma comer enquanto estuda ou faz a } \\
\text { tarefa escolar? }\end{array}$ & 0,574 & & & 0,348 \\
\hline EA25 & $\begin{array}{l}\text { Você costuma se esquecer de fazer as tarefas } \\
\text { escolares que são pedidas? }\end{array}$ & 0,641 & & & 0,465 \\
\hline EA26 & $\begin{array}{l}\text { Você costuma se distrair ou pensar em outra coisa } \\
\text { quando esta lendo ou fazendo a tarefa escolar? }\end{array}$ & 0,650 & & & 0,468 \\
\hline EA27 & $\begin{array}{l}\text { Quando você percebe que não entendeu o que leu, } \\
\text { costuma parar e ler novamente? }\end{array}$ & & & & 0,213 \\
\hline EA28 & Você costuma se esquecer de fazer a tarefa escolar? & 0,627 & & & 0,441 \\
\hline EA29 & $\begin{array}{l}\text { Você percebe quando não entende o que esta } \\
\text { lendo? }\end{array}$ & & & 0,542 & 0,298 \\
\hline EA30 & $\begin{array}{l}\text { Você costuma estudar ou fazer a tarefa escolar } \\
\text { assistindo televisão? }\end{array}$ & 0,356 & & & 0,136 \\
\hline EA31 & $\begin{array}{l}\text { Você costuma pedir ajuda ao colega ou a alguém } \\
\text { de sua casa, quando não entende alguma matéria? }\end{array}$ & & & & 0,089 \\
\hline
\end{tabular}

\& Santos, 2006; Oliveira et al., 2010), por outro lado, o alfa de Cronbach da subescala Estratégias Metacognitivas $(0,57)$ não pode ser considerado aceitável. Esse valor de alfa para a subescala Estratégias Metacognitivas ficou abaixo do limite $(0,60)$ para ser considerado consistente internamente (Prieto \& Muñiz, 2000). Os alfas de Cronbach da escala toda $(0,74)$ e das subescalas Ausência de Estratégias de Aprendizagem $(0,77)$ e Estratégias Cognitivas $(0,73)$ foram considerados aceitáveis.

Cabe a ressalva, sob o aspecto tratado, que os itens 18, 27 e 31, relacionados à utilização de estratégias metacognitivas, denotam uma atenção merecida, já que não carregaram em nenhum dos três fatores da escala. O item 18 era representativo de estratégias de regulação, o item 27 representativo das estratégias de autopercepção e o item 31, de estratégias de planejamento. Uma hipótese seria de que esses itens provavelmente apresentaram problemas durante a sua formulação, proporcionando equívocos de entendimento por parte dos alunos.

A provável razão de uma das subescalas não apresentar consistência interna pode estar ligada, hipoteticamente, à construção da medida, tendo em vista que, originalmente, as questões relacionadas à subescala são estratégias de regulação, autopercepção e planejamento, geralmente utilizadas quando o aluno retoma os estudos em casa, como tarefas ou preparação para as provas. Todavia, a modalidade de ensino trabalha com um conteúdo mais prático e dinâmico, enfatizando as atividades em sala de aula ou laboratórios. Assim sendo, há possibilidade de má interpretação das questões ou ainda a falta de sentido nelas para os alunos.

A pesquisa propôs o estudo de parâmetros psicométricos (evidências de validade fatorial) de uma escala de estratégias de aprendizagem destinada a 
Tabela 2

Itens das Subescalas e Alfa de Cronbach

\begin{tabular}{|c|c|c|c|}
\hline Itens & & Fator & $\begin{array}{l}\text { Alpha de } \\
\text { Cronbach }\end{array}$ \\
\hline EA3 & Você costuma estudar ou fazer as tarefas escolares na última hora? & \multirow{12}{*}{ 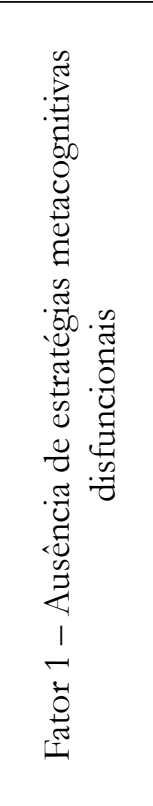 } & \multirow{12}{*}{0,77} \\
\hline EA7 & Você costuma desistir quando uma tarefa é difícil ou chata? & & \\
\hline EA8 & Você costuma se distrair durante a explicação em sala de aula? & & \\
\hline EA12 & Você se sente cansado quando estuda, ou faz a tarefa escolar? & & \\
\hline EA15 & $\begin{array}{l}\text { Você costuma ficar pensando em outra coisa quando o professor está dando } \\
\text { explicações? }\end{array}$ & & \\
\hline EA21 & Quando você esta fazendo uma tarefa difícil, costuma ficar muito nervoso? & & \\
\hline EA23 & $\begin{array}{l}\text { Depois que você senta para fazer a tarefa escolar, costuma ficar se levantando } \\
\text { todo hora para pegar algum material? }\end{array}$ & & \\
\hline EA24 & Você costuma comer enquanto estuda ou faz a tarefa escolar? & & \\
\hline EA25 & Você costuma se esquecer de fazer as tarefas escolares que são pedidas? & & \\
\hline EA26 & $\begin{array}{l}\text { Você costuma se distrair ou pensar em outra coisa quando esta lendo ou fazendo } \\
\text { a tarefa escolar? }\end{array}$ & & \\
\hline EA28 & Você costuma se esquecer de fazer a tarefa escolar? & & \\
\hline EA30 & Você costuma estudar ou fazer a tarefa escolar assistindo televisão? & & \\
\hline EA1 & Você costuma grifar as partes importantes do texto para aprender melhor? & \multirow{11}{*}{ 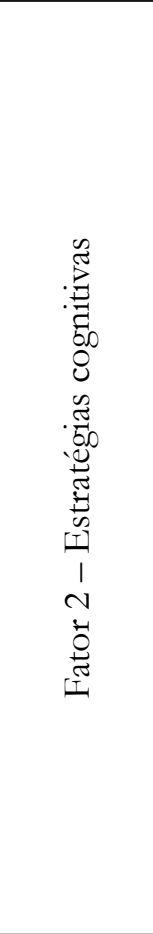 } & \multirow{11}{*}{0,73} \\
\hline EA2 & $\begin{array}{l}\text { Quando você esta construindo um texto, costuma fazer uma lista de ideias antes } \\
\text { de começar a escrever? }\end{array}$ & & \\
\hline EA4 & $\begin{array}{l}\text { Quando você está assistindo a uma aula, costuma fazer anotações por conta } \\
\text { própria? }\end{array}$ & & \\
\hline EA5 & $\begin{array}{l}\text { Você costuma ler outros textos e livros sobre o assunto que o professor explicou } \\
\text { em aula? }\end{array}$ & & \\
\hline EA9 & Você costuma fazer um esquema usando as ideias principais do texto? & & \\
\hline EA10 & $\begin{array}{l}\text { Quando você termina de estudar para uma prova, costuma fazer questões, para si } \\
\text { próprio, para ver se entendeu bem o que estudou? }\end{array}$ & & \\
\hline EA11 & $\begin{array}{l}\text { Quando você lê um texto, procura escrever com suas palavras o que entendeu da } \\
\text { leitura, para poder estudar depois? }\end{array}$ & & \\
\hline EA14 & $\begin{array}{l}\text { Quando você estuda, lê a matéria e depois fecha o caderno e fala em voz alta } \\
\text { tudo o que entendeu? }\end{array}$ & & \\
\hline EA16 & $\begin{array}{l}\text { Quando você aprende alguma coisa nova, costuma tentar relacionar aquilo que } \\
\text { está prendendo com alguma coisa que você já sabia? }\end{array}$ & & \\
\hline EA17 & Você resume os textos que o professor pede para estudar? & & \\
\hline EA20 & Você cria perguntas e respostas sobre o assunto que esta estudando? & & \\
\hline EA6 & $\begin{array}{l}\text { Quando você estuda, costuma perceber que não esta entendendo aquilo que está } \\
\text { estudando? }\end{array}$ & \multirow{4}{*}{ 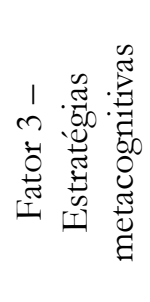 } & \multirow{4}{*}{0,57} \\
\hline EA13 & $\begin{array}{l}\text { Você percebe quando está com dificuldade para aprender determinados assuntos } \\
\text { ou matérias? }\end{array}$ & & \\
\hline EA22 & Quando você estuda, percebe que não esta conseguindo aprender? & & \\
\hline EA29 & Você percebe quando não entende o que esta lendo? & & \\
\hline
\end{tabular}


Tabela 3

Estatística Descritiva da Escala

\begin{tabular}{lccccc}
\hline Subescala & $\begin{array}{c}\text { Variação da } \\
\text { pontuação }\end{array}$ & $\begin{array}{c}M \text { de pontos } \\
\text { na escala }\end{array}$ & DP & $\begin{array}{c}\text { Pontuação } \\
\text { mínima }\end{array}$ & $\begin{array}{c}\text { Pontuação } \\
\text { máxima }\end{array}$ \\
\hline $\begin{array}{l}\text { Ausência de estratégias } \\
\text { metacognitivas disfuncionais }\end{array}$ & $0-24$ & 12,62 & 3,89 & 2 & 24 \\
Estratégias cognitivas & $0-22$ & 10,01 & 3,99 & 1 & 20 \\
Estratégias metacognitivas & $0-8$ & 4,01 & 1,54 & 0 & 8 \\
\hline
\end{tabular}

alunos do ensino fundamental adaptada à utilização no ensino técnico profissional. Todavia, os resultados demonstram a necessidade de maior investigação com o intuito de proporcionar uma escala ainda mais apropriada para aplicação, em vista que ela apresentou imperfeição para uma subescala. Baseada nos escores, a adaptação da medida não foi suficiente para mapear a utilização das estratégias metacognitivas no ensino técnico profissional.

Quanto ao segundo objetivo do presente estudo, o de levantar dados descritivos das estratégias de aprendizagem nos estudantes do ensino profissionalizante, os resultados evidenciaram que se pode considerar que parte significativa dos estudantes relata recorrer às estratégias de aprendizagem, de acordo com a média de pontos atingidos, 28,1. Os dados encontrados no presente estudo são considerados positivos e vai ao encontro do que pesquisadores, como Dansereau (1985), Pozo (1996) e Boruchovitch (1999), professam, isto é, que a utilização de estratégias de aprendizagem contribui para o processo de aprendizagem, permitindo que o aluno possa recuperar posteriormente à informação, contribuindo diretamente em seu bom desempenho.

Outro dado levantado pelo estudo é que as estratégias cognitivas são mais empregadas pelos estudantes no ensino técnico profissional, fato explicado supostamente pelo fato de a modalidade dar ênfase nas atividades práticas durante o desenvolvimento do curso. Hipotetiza-se que as estratégias cognitivas exigem ações mais concretas para efetivar o aprendizado (como exemplo, resumir, grifar, ler e repetir) e, portanto, talvez se adequasse mais ao ensino profissional, que teria também essa característica em razão da grande quantidade de atividades práticas profissionais. Supostamente, o aluno do ensino profissional seria direcionado à prática, talvez carecendo de inserções que o levassem a pensar e a compreender o próprio processo de aprender (comportamento metacognitivo). Para Castro (2003), a educação profissional deve ser encarada não como uma maneira rápida e conveniente de ensinar aos alunos simples habilidades, pelo contrário, a educação profissional é uma forma de colaborar com a disseminação de novas tecnologias e melhores práticas produtivas. Nesse sentido, pondera-se que os dados encontrados no presente estudo parecem indicar uma necessidade de que o aluno do ensino profissionalizante seja mais incentivado ao pensamento crítico e reflexivo acerca do próprio aprendizado.

Esse dado é interessante e merece ser mais bem investigado em pesquisas futuras, haja vista que os estudos de Oliveira et al. (2010) revelaram que. à medida que os estudantes ficam mais velhos, eles parecem recorrer com menos frequência às estratégias cognitivas e se tornam mais metacognitivos em relação ao aprendizado. Porém, mesmo que o estudante mais velho tenha maior percepção sobre a sua capacidade de aprender a aprender (habilidade metacognitiva), o que, presumivelmente, o levaria a empregar e diversificar o uso de estratégias no momento do estudo, curiosamente, esse estudante, com o passar das séries, menciona deixar de lado a utilização de estratégias.

O dado encontrado na presente investigação não encontra apoio teórico, uma vez que é controverso, mas algumas hipóteses podem ser aventadas, sobretudo quando se considera que o contexto escolar pouca atenção tem dado ao ensino e à manutenção do uso das estratégias de aprendizagem e no ensino profissionalizante essa realidade não é diferente. Enfatiza-se muito mais a suposta incapacidade do aluno em aprender do que, de fato, a potencialização do aprendizado crítico.

Acrescenta-se que não foram encontrados estudos em âmbito nacional, até o presente momento, que tivessem focado esse tipo de aluno com as especificidades das instituições de ensino às quais eles estudavam. Assim sendo, embora o presente estudo tenha contribuído para a ampliação das considerações sobre o assunto, esse dado deve ser mais bem 
explorado. Posto isso, constata-se que os achados da presente pesquisa somam-se aos estudos anteriores, acerca do uso e da diversificação das estratégias de aprendizagem no momento do estudo. Ressalva-se, no entanto, a necessidade de novas investigações sobre o tema.

\section{Considerações Finais}

No levantamento dos estudos aplicados em nível universitário, Boruchovitch et al. (2005) apontaram que os alunos de uma forma geral não utilizam, ou até mesmo desconhecem estratégias de aprendizagem. O estudo em questão não difere quanto à utilização de estratégias no ensino técnico profissional. O professor também deve garantir o desenvolvimento de estratégias por parte dos alunos, explorando profundamente com a busca de novos conteúdos e informações. $\mathrm{O}$ uso das estratégias possibilita ao indivíduo instrumentos para potencializar os estudos, permitindo entender e compreender a informação, considerados processos básicos em qualquer aprendizagem e realização cognitiva, além dos processos metacognitivos de planejar, monitorar e regular a aprendizagem.

O presente estudo buscou preencher a falta de instrumentos destinados a essa avaliação e também a falta de estudos para essa modalidade de ensino. No que se refere à análise fatorial da escala, o instrumento busca preencher a lacuna de instrumentos destinados a avaliar as estratégias. Cabe a ressalva de que novos estudos devem ser efetuados para consolidação dos resultados. De forma geral, os aspectos positivos do presente estudo são relevantes, as estratégias de aprendizagem podem ser estudadas em diferentes contextos, mas sempre respeitando o conhecimento empírico acerca dos instrumentos utilizados para contribuir para um crescimento amplo e diversificado.

\section{Referências}

Bartalo, L. (2006). Mensuração de estratégias de estudo e aprendizagem de alunos universitários: learning and study strategies inventory (LASSI) adaptação e validação para o Brasil (Tese de doutorado). Universidade Estadual Paulista Júlio de Mesquita Filho, Marília-SP.

Boruchovitch, E. (1995). A identificação e o estudo das variáveis associadas ao fracasso escolar brasileiro. Projeto de pesquisa realizado na qualidade de bolsista de recém doutor do CNPq. Faculdade de
Educação, Departamento de Psicologia Educacional, Universidade de Campinas.

Boruchovitch, E. (1999). Estratégias de aprendizagem e desempenho escolar: Considerações para a prática educacional. Psicologia: Reflexão e Crítica, 12(2), 361376. doi: 10.1590/S0102-79721999000200008

Boruchovitch, E., \& Santos, A. A. A. (2004). Escala de avaliação de estratégias de aprendizagem para crianças do ensino fundamental. Manuscrito não publicado. Universidade São Francisco, Bragança Paulista, SP.

Boruchovitch, E., \& Santos, A. A. A. (2006). Estratégias de aprendizagem: conceituação e avaliação. In A. P. P. Noronha \& F. F. Sisto (Eds.), Facetas do fazerer em avaliação psicológica (pp. 10-20). São Paulo: Vetor.

Boruchovitch, E., \& Santos, A. A. A. (2006). Estratégias de aprendizagem: Conceituação e avaliação. In A. P. P. Noronha \& F. F. Sisto (Ed.), Facetas do fazer em avaliação psicológica (pp. 10-20). São Paulo: Vetor.

Boruchovitch, E., Costa, E. R., \& Neves, R. R. C. (2005). Estratégias de aprendizagem: Contribuições para a formação de professores nos cursos superiores. In M. C. R. A. Joly, A. A. A. Santos \& F. F. Sisto (Ed.), Questões do Cotidiano Universitário (pp. 239-260). São Paulo: Casa do Psicólogo.

Boruchovitch, E., Santos, A. A. A., Costa, E. R., Neves, E. R. C., Cruvinel, M. Primi, R., \& Guimarães, S. E. R. (2006). Estudo preliminar para construção de uma escala de estratégias de aprendizagem infantil. Psicologia: Teoria e Pesquisa, 22(3), $297-$ 304. Recuperado de http://www.scielo.br/scielo. php?script $=$ sci_nlinks\&ref $=000090 \&$ pid $=$ S0102$-3772200900040000800006 \& \operatorname{lng}=\mathrm{en}$

Cardoso, L. R. (2002). Uso de estratégias de aprendizagem e suas relaçoes com metas de realização: Um estudo no ensino superior (Dissertação de mestrado). Universidade Estadual de Londrina, Londrina-PR.

Carvalho, M. R. (2006). Estratégias metacognitivas de leitura utilizadas de $2^{a}$ a $4^{a}$ séries do Ensino Fundamental (Dissertação de mestrado). Universidade São Franscisco, Itatiba.

Castro, C. M. (2003). O despertar do gigante: Com menos ufanismo e mais direção, a educaşão brasileira acorda. Belo Horizonte: MG-Ed. Universidade.

Dansereau, D. F. (1985). Learning strategy research. In J. W. Segal, S. F. Chipman \& R. Glaser (Ed.), 
Thinking and learning skills (pp. 209-239). Hillsdale, $\mathrm{Nj}$ : Lawrence Erlbaum.

Decreto-Lei $n^{\circ}$ 2.208, de 17 de abril de 1997. Regulamenta o $\$ 2^{\circ}$ do art. 36 e os arts. 39 a 42 da Lei $n^{\circ}$ 9.394, de 20 de dezembro de 1996, que estabelece as diretrizes e bases da educação nacional. Diário Oficial [da] República Federativa do Brasil, Brasília, D.F., 17 abr. 1997. Seção 3, p. 13.

Decreto-Lei $n^{\circ} 4.073$, de 30 de janeiro de 1942. Lei orgânica do ensino industrial, que estabelece as bases de organização e de regime do ensino industrial que é o ramo de ensino, de grau secundário, destinado à preparação profissional dos trabalhadores da indústria e das atividades artesanais e, ainda, dos trabalhadores dos transportes, das comunicações e da pesca. Coleção das Leis do Brasil, Rio de Janeiro, DF, 31 dez. 1942.

Decreto-Lei no 6.141, de 28 de dezembro de 1943. Lei Orgânica do Ensino Comercial. Estabelece as bases de organização e de regime do ensino comercial, que é o ramo de ensino de segundo grau. Diário Oficial [da] República Federativa do Brasil, Brasília, D.F., 31 dez. 1943. Seção 1, pt. 1, p. 209.

Decreto-lei no 9.613 , de 20 de agosto de 1946. Estabelece as bases de organização e de regime do ensino a agrícola, que é o ramo do ensino até o segundo grau, destinado essencialmente à preparação profissional dos trabalhadores da agricultura. Diário Oficial [da] República Federativa do Brasil, Brasília, D.F., 23 ago. 1946. Seção 1, pt. 1, p. 12019.

Dembo, M. H. (1994). Applying educational psychology (5th ed.). New York: Longman Publishing Group.

Ferreira, L. F. (2007). Estratégias de aprendizagem do aluno de $5^{a}$ série na resolução de situação-problema (Dissertação de mestrado). Faculdade de Educação. Pontifícia Universidade Católica do Paraná, Curitiba, PR.

Flavell, J. H. (1987). Speculations about the nature and development of Metacognition. In F. E. Weinert \& R. Kluwe (Org.). Metacognition, motivation, and understanding. (pp. 1-16). Hillsdale, N. J: Erlbaum.

Garner, R., \& Alexander, P.A. (1989). Metacognition: Answered and unanswered questions. Educational Psychologist, 24, 143-158. doi: 10.1207/ s15326985ep2402_2

Gomes, M. A. M. (2002). A aprendizagem autorregulada em leitura numa perspectiva de jogo de regras (Dissertação de mestrado). Faculdade de Educação. Universidade Estadual de Campinas, Campinas-SP.

Gomes, M. A. M., \& Boruchovitch, E. (2005). Desempenho no jogo, estratégias de aprendizagem e compreensão na leitura. Psicologia: Teoria e Pesquisa, 21(3), 319-326. Recuperado de http://www.scielo. $\mathrm{br} / \mathrm{pdf} / \mathrm{ptp} / \mathrm{v} 21 \mathrm{n} 3 / \mathrm{a} 08 \mathrm{v} 21 \mathrm{n} 3 . \mathrm{pdf}$

Hadwin, A. F., Winne, P. H., Stockley, D. B., Nesbit, J. C., \& Woszczyna, C. (2001).Context moderates student's self-reports about how they study. Journal of Educational Psychology, 93, 477-487. doi: 10.1037//O022-0663.93.3.477

Jamieson, J. (1995). The cognitive styles of reflection/ impulsivity and field independence/dependence and ESL success. In H. D. Brown \& S. T. Gonzo (Ed. Readings on second language acquisition (pp. 119137). Illinois: Prentice Hall Inc.

Joly, M. C. R. A. (2006). Escala de estratégias de leitura para etapa inicial do ensino fundamental. Estudos de Psicologia, 23(3), 271-278. doi: 10.1590/ S0103-166X2006000300006

Kuenzer, A. Z. (2002). Exclusão includente e inclusão excludente. In J. Lombardi, D. Saviani \& J. L. Sanfelice (Ed.), Capitalismo, trabalho e educação (pp. 77-96). Campinas: Autores Associados.

Kuenzer, A. Z. (2002). Exclusão includente e inclusão excludente. In J. Lombardi, D. Saviani \& J. L. Sanfelice (Ed.), Capitalismo, trabalho e educação (pp. 77-96). Campinas: Autores Associados.

Lei $n^{\circ}$ 5.692/71, de 11 de agosto de 1971. Fixa diretrizes e bases para o ensino de $1^{\circ}$ e $2^{\circ}$ graus, e dá outras providências. Diário Oficial [da] República Federativa do Brasil, Brasília, D.F., 12 ago. 1971. Seção 1, pt. 1, p. 6377.

Lei $\mathrm{n}^{\circ}$ 7.044/82, de 18 de outubro de 1982. Altera dispositivos da Lei 5.692, de 11 de agosto de 1971, referentes à profissionalização do ensino de $2^{\circ}$ grau. Diário Oficial [da] República Federativa do Brasil, Brasília, D.F., 19 out. 1982. Seção 1, pt. 1, p. 19539.

Lei $\mathrm{n}^{\circ}$ 10.683, de 28 de maio de 2003. Dispõe sobre a organização da Presidência da República e dos Ministérios, e dá outras providências. Diário Oficial [da] República Federativa do Brasil, Brasília, D.F., 29 mai. 2003. Seção 1, p. 2.

Machado, O. A. (2005). Evasão de alunos de cursos superiores: Fatores motivacionais e de contexto (Dissertação 
de mestrado). Universidade Estadual de Londrina, Londrina-PR.

Machado, O. A., Bzuneck, J. A., \& Guimarães, S. R. (2004). Inventário de motivação e estratégias em cursos superiores. Manuscrito não Publicado do Programa de Pós-Graduação em Educação da Universidade Estadual de Londrina. Londrina.

Oliveira, K. L. (2008). Escala de estratégias de aprendizagem para o ensino fundamental: Análise de suas propriedades psicométricas (Tese de Doutorado). Universidade Estadual de Campinas, Campinas-SP.

Oliveira, K. L., Boruchovitch, E., \& Santos, A. A. A. (2006) Escala de estratégias de aprendizagem: Estudo das propriedades psicométricas. In C. Machado, L. Almeida, M. A. Guisande, M. Gonçalves \& V. Ramalho (Ed.), XI Conferência Internacional Avaliação Psicológica: formas e contextos (pp. 509-516). Braga: Psiquilibrios Edições.

Oliveira, K. L., Boruchovitch, E., \& Santos, A. A. A. (2010). Escala de avaliação das estratégias de aprendizagem para o ensino fundamental - EAVAP-EF. São Paulo: Casa do Psicólogo.

Oliveira, K. L., Boruchovitch, E., \& Santos, A. A. A. (2011). Estratégias de aprendizagem no ensino fundamental: Análise por gênero, série escolar e idade. Psico (PUCRS. Impresso), 42, 98-105. Recuperado de http://revistaseletronicas.pucrs.br/ojs/ index.php/revistapsico/article/view/6273/6305

Padilha, H. M. F. (2001). O mundo da educação (3a ed.). Brasília: SENAI/DN.

Pascualon, J. F. (2011). Escala de avaliação da metacognição infantil: Elaboração de itens e análise dos parâmetros psicométricos (Dissertação de mestrado). Universidade Federal de São Carlos, São Carlos-SP.

Perassinoto, M. G. M., Boruchovitch, E., \& Oliveira, K. L. (2012). Estratégias de aprendizagem no ensino fundamental: Revisitando instrumentos de medida. In E. Boruchovitch, A. A. A. Santos \& E. Nascimento (Ed.), Avaliação psicológica nos contextos educativo e psicossocial (pp. 53-77). São Paulo: Casa do Psicólogo.

Pintrich, P. R. (1989). The dynamic interplay of student motivation and cognition in the college classroom. In M. L. Maehr \& C. Ames (Ed.), Advances in Motivation and Achievement: Motivation Enhancing Environments (pp 117-160). Greenwich, CT: JAI Press.
Pintrich, P. R., \& Groot, E. V. (1989). Motivational and self-regulated learning components of classroom academic performance. Journal of Educational Psychology, 82(1), 33-40. Recuperado de http:// web.stanford.edu/dept/SUSE/projects/ireport/ articles/self-regulation/self-regulated $\% 20$ learning-motivation.pdf

Piovezan, N. M., \& Castro, N. R. (2008). Compreensão e estratégias de leitura no Ensino Fundamental. PSIC - Revista de Psicologia da Vetor Editora, 9(1), 53-62. Recuperado de http://pepsic.bvsalud.org/ pdf/psic/v9n1/v9n1a07.pdf

Portilho, E. M. L.; Ferreira, L. F. (2005). O Fracasso Escolar na Quinta Série: um estudo preliminar. In: $\checkmark$ Educere - III Congresso Nacional da Área de Educação (pp. 627-636). Curitiba: Curitiba PUCPR.

Pozo, J. I. (1996). Estratégias de Aprendizagem. In C. Coll, J. Palácios, \& A. Marchesi (Org.), Desenvolvimento psicológico e educação: Psicologia da educação (pp 176-197). Porto Alegre: Artmed.

Prieto, G., \& Muñiz, J. (2000). Um modelo para evaluarlacalidad de lostests utilizados em España. Recuperado de http://www.cop.es/tests/modelo.htm

Scacchetti, F. A. P., \& Oliveira, K. L. (2012). Escala de avaliação das estratégias de aprendizagem para o ensino fundamental (EAVAP-EF) adaptada para uso no ensino técnico profissional. Manuscrito não publicado do Programa de Mestrado em Educação da Universidade Estadual de Londrina, Londrina-PR.

Serafim, T. M. (2009). A estratégia de pedir ajuda de estudantes do Ensino Fundamental (Dissertação de mestrado). Universidade Estadual de Campinas, Campinas.

Serafim, T. M., \& Boruchovitch, E. (2007). Pedir ajuda: Uma estratégia de aprendizagem de estudantes do ensino fundamental. As estratégias de aprendizagem e o gênero entre escolares. VIII Congresso Nacional de Psicologia Escolar e Educacional [CD-ROM]. Associação Brasileira de Psicologia Escolar e Educacional. São João del Rei.

Stahl, N. A., King, J. R., \& Eliers, U. (1996). Postsecondary reading strategies rediscovered. Journal of adolescent \& Adult literacy, 39 (5), 368379. Recuperado de http://www.jstor.org/ stable/40014658?seq=1\#page_scan_tab_contents

Valle, A. A., Cabanach, R. G., Cuevas, L. M., Rodriguez, S., \& Baspino, M. (1998). Las estrategias de 
aprendizaje: Características básicas y su relevancia en el contexto escolar. Revista de Ciencias de la Educación, 175, 319-332. Recuperado de http://www. redalyc.org/articulo.oa?id $=17514484006$

Veenman, M. V. J., Wilhelm, P., \& Beishuizen, J. J. (2004). The relation between intellectual and metacognitive skills from a developmental perspective. Learning and Instruction, 14, 89-109. doi:10.1016/j. learninstruc.2003.10.004

Weinstein, C. E., Zimmermman, S. A., \& Palmer, D. R. (1988). Assessing learning strategies: the design and development of the LASSI. In C. E. Weinstein, E. T. Goetz \& P. A. Alexander (Ed.), Learning and study strategies: Issues in assessment, instruction and evaluation (pp 25-40). Educational Psychology Series. San Diego: Academic Press.

Zimmerman, B. J., \& Martinez-Pons, M. (1986). Development of a structured interview for assessing student use of self-regulated learning strategies. American Educational Research Journal, 23, 614-628. doi: 10.3102/00028312023004614

Recebido: $16 / 12 / 2013$ Primeira reformulação: 08/07/2014 Segunda reformulação: 10/12/2014 Aprovado: 11/02/2015

Sobre os autores:

Fabio Alexandre Pereira Scacchetti é engenheiro têxtil, mestre em Educação pelo programa de Pós-graduação Stricto Sensu em Educação da Universidade Estadual de Londrina e professor assistente do curso de Engenharia Têxtil na Universidade Tecnológica Federal do Paraná.

E-mail: fabioscacchetti@utfpr.edu.br

Katya Luciane de Oliveira é psicóloga, mestre em Psicologia pelo Programa de Estudos de Pós-graduação Stricto Sensu em Psicologia da Universidade São Francisco, doutora em Psicologia, Desenvolvimento Humano e Educação pela Faculdade de Educação da Unicamp e professora adjunta do curso de Psicologia e do Programa de Mestrado em Educação da Universidade Estadual de Londrina.

E-mail:katyauel@gmail.com

Ana Elisa da Costa Moreira é pedagoga no Colégio Estadual Professora Maria do Rosário Castaldi, regente de alfabetização da Escola Municipal Bartolomeu de Gusmão e mestre em Educação pelo programa de Pós-graduação Stricto Sensu em Educação da Universidade Estadual de Londrina.

E-mail: ana_elisa_cm@yahoo.com.br

Contato com os autores:

Fabio Alexandre Pereira Scacchetti

E-mail: fabioscacchetti@utfpr.edu.br

Universidade Tecnológica Federal do Paraná

Rua Marcílio Dias, 635 - Apucarana-PR

CEP: 86812-460 